\title{
Does weight gain, throughout 15 years follow-up after Nissen laparoscopic fundoplication, compromise reflux symptoms control?
}

\author{
O ganho do peso no seguimento de 15 anos após Nissen laparoscópico compromete o controle dos sintomas \\ de refluxo?
}

\author{
Victor Ramos Mussa DIB ${ }^{1 \odot}$, Almino Cardoso RAMOS ${ }^{2}{ }^{\circ}$, Nilton Tokio KAWAHARA ${ }^{3 \odot}$, Josemberg \\ Marins CAMPOS $^{4}{ }^{\oplus}$, João Caetano MARCHESINI ${ }^{5 \odot}$, Manoel GALVÃO-NETO ${ }^{2 \odot}$, Adriana Gonçalves \\ Daumas Pinheiro GUIMARÃES ${ }^{6}{ }^{\circ}$, Adriano Pessoa PICANÇO-JUNIOR ${ }^{7}{ }^{\circ}$, Carlos Eduardo DOMENE $^{3 \odot}$
}

\begin{abstract}
Background: Gastroesophageal reflux disease is defined by the abnormal presence of gastric content in the esophagus, with $10 \%$ incidence in the Western population, being fundoplication one treatment option. Aim: To evaluate the early (six months) and late (15 years) effectiveness of laparoscopic fundoplication, the long term postoperative weight changes, as well as the impact of weight gain in symptoms control. Methods: Prospective study of 40 subjects who underwent laparoscopic Nissen's fundoplication. Preoperatively and early postoperatively, clinical, endoscopic, radiologic, manometric and pHmetric evaluations were carried out. After 15 years, clinical and endoscopic assessments were carried out and the results compared with the early ones. The presence or absence of obesity was stratified in both early and late phases, and its influence in the long-term results of fundoplication was studied, measuring quality of life according to the Visick criteria. Results: The mean preoperative ages, weight, and body mass index were respectively, 51 years, $69.67 \mathrm{~kg}$ and $25.68 \mathrm{~kg} / \mathrm{m}^{2}$. The intraoperative and postoperative complications rates were $12.5 \%$ and $15 \%$, without mortality. In the early postoperative period the symptoms were well controlled, hernias and esophagitis disappeared, the lower esophageal sphincter had functional improvement, and pHmetry parameters normalized. In the late follow-up 29 subjects were assessed. During this period there was adequate clinical control of reflux regardless of weight gain. In both time periods Visick criteria improved. Conclusion: Fundoplication was safe and effective in early and late periods. There was late weight gain, which did not influence effective symptoms control.
\end{abstract}

HEADINGS - Gastroesophageal reflux. Fundoplication. Endoscopy.

RESUMO - Racional: A doença do refluxo gastroesofágico é definida pela presença anormal do conteúdo gástrico no esôfago com incidência de $10 \%$ na população ocidental, sendo a fundoplicatura uma das opções de tratamento. Objetivo: Avaliar a efetividade precoce (seis meses) e tardia (15 anos) da fundoplicatura laparoscópica, bem como a evolução ponderal pós-operatória em longo prazo, e o impacto do ganho de peso no controle tardio dos sintomas. Métodos: Estudo prospectivo com 40 indivíduos submetidos à fundoplicatura laparoscópica pela técnica de Nissen. No pré e pós-operatório precoce, foram realizadas avaliações clínica, endoscópica, radiológica, manométrica e pHmétrica. Após 15 anos, realizaram-se avaliações clínica e endoscópica, comparando-se os resultados com os da fase precoce. Estratificou-se a presença ou ausência de obesidade nestas fases e estudou-se sua influência nos resultados em longo prazo, mensurando-se a qualidade de vida pelos critérios de Visick. Resultados: As médias de idade, peso e do índice de massa corporal pré-operatórias foram 51 anos, $69.67 \mathrm{~kg}$ e $25,68 \mathrm{~kg} / \mathrm{m}^{2}$. O índice de complicações intra e pós-operatórias foram $12,5 \%$ e $15 \%$, sem mortalidade. No pós-operatório precoce houve controle dos sintomas, remissão das hérnias e esofagites, melhora funcional do esfíncter esofágico inferior e normalização dos parâmetros pHmétricos. No seguimento tardio, 29 indivíduos foram acompanhados. Nesta fase, houve adequado controle clínico do refluxo, independente do ganho de peso. Em ambas as fases houve melhora nos critérios de Visick. Conclusão: A fundoplicatura foi segura e efetiva, precoce e tardiamente. Houve ganho de peso tardio, o que não influenciou no controle efetivo dos sintomas.

DESCRITORES: Refluxo gastroesofágico. Fundoplicatura. Endoscopia.

\begin{tabular}{|c|c|c|c|c|c|}
\hline \multirow{3}{*}{ Variables } & \multicolumn{4}{|c|}{ Assessment } & \multirow[b]{3}{*}{$\mathrm{p}^{*}$} \\
\hline & \multicolumn{2}{|r|}{ Pre } & \multicolumn{2}{|c|}{ Late post } & \\
\hline & $f_{i}$ & $\%$ & $f_{i}$ & $\%$ & \\
\hline Esophagitis & & & & & $<0.001$ \\
\hline Yes & 30 & 75.0 & 3 & 10.3 & \\
\hline No & 10 & 25.0 & 26 & 89.7 & \\
\hline Total & 40 & 100.0 & 29 & 100.0 & \\
\hline Axial hiatal hernia & & & & & $<0.001$ \\
\hline Yes & 39 & 97.5 & 2 & 6.9 & \\
\hline No & 1 & 2.5 & 27 & 93.1 & \\
\hline Total & 40 & 100.0 & 29 & 100.0 & \\
\hline
\end{tabular}

Central message

Laparoscopic fundoplication is one of the best treatment options for correcting gastroesophageal reflux disease. However, the influence of increasing obesity in the late postoperative period on the efficiency of the technique is still little known. A study in up to 15 years shows the impact of weight gain on delayed symptom control.

\section{Perspective}

Prospective study of individuals submitted to laparoscopic Nissen having the same evaluation data made in the early postoperative period and after 15 years - stratifying the presence or absence of obesity in these phases - - showed fundoplication be safe and effective, in early and late follow-up. In those who gained weight in late evaluation, it was found that the acquired obesity did not influence the effective control of symptoms.

From the ${ }^{1}$ Instituto Victor Dib, Manaus, AM, Brasil; ${ }^{2}$ Gastro Obeso Center, São Paulo, SP, Brasil; ${ }^{3}$ Faculdade de Medicina, Universidade de São Paulo, São Paulo, SP, Brasil; ${ }^{4}$ Universidade Federal de Pernambuco, Recife, PE, Brasil; ${ }^{5}$ Clínica Caetano Marchesini, Curitiba, PR, Brasil; ' 5 Serviço de Cirurgia da Aeronáutica, Manaus, AM, Brasil; ${ }^{7}$ Universidade Federal do Amazonas, Manaus, AM

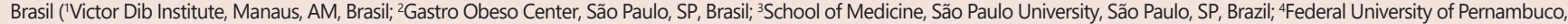
Recife, PE, Brazil; ${ }^{5}$ Caetano Marchesini Clinic, Curitiba, PR, Brazil; ${ }^{6}$ Airforce Surgical Center, Manaus, AM, Brazil; ${ }^{7}$ Federal University of Amazonas, Manaus, AM, Brazil).

How to cite this article: Dib VRM, Ramos AC, Kawahara NT, Campos JM, Marchesini JC, Galvão-Neto M, Guimarães AGDP, Picanço-Junior AP, Domene CE. Does weight gain, throughout 15 years follow-up after Nissen laparoscopic fundoplication, compromise reflux symptoms control? ABCD Arq Bras Cir Dig. 2020;33(1):e1488. DOI: /10.1590/0102-672020190001e1488

Correspondence:

Victor Ramos Mussa Dib

E-mail:vr.dib@bol.com.br
Financial source: none

Conflict of interest: none

Received for publication: 15/10/2019

Accepted for publication: 14/01/2020 
INTRODUCTION

G astroesophageal reflux disease (GERD) is defined by the abnormal presence of gastric content above the lower esophageal sphincter (LES), causing a variable spectrum of symptoms and complications ${ }^{30}$. It affects approximately $10 \%$ of the Western population ${ }^{18,19}$. The most frequent clinical manifestations are pyrosis and regurgitation ${ }^{29}$. The disease is often controlled through clinical measures ${ }^{12}$ and surgery is reserved for patients with failed clinical treatment, advanced erosive esophagitis, Barrett's esophagus, peptic stenosis or when the patient demands the operation ${ }^{12,20,28,29,34}$. Despite the clinical treatment, some risk factors for disease progression are nocturnal reflux, low-pressure LES, and early erosive esophagitis ${ }^{9}$.

Minimally invasive surgery has rendered fundoplication more frequent ${ }^{9}$ with results similar to laparotomy ${ }^{3,30}$. However, the long-term surgical effectiveness is still a matter of discussion ${ }^{30}$.

Postoperative weight gain may lead to fundoplication failure to contain reflux due to the increase in intra-abdominal pressure and modification of the gastroesophageal pressure gradient ${ }^{14,23}$. In this case, a new surgery may be necessary to control weight and preserve the anti-reflux mechanism. Gastric bypass with jejunal diversion seems to be the best option for this purpose, however with relevant associated morbidity ${ }^{29}$.

The objectives of this study were to evaluate the safety of laparoscopic fundoplication, its effectiveness in the early (six months) and late (15 years) control of reflux symptoms, and the influence of postoperative weight gain on late reflux control.

\section{METHODS}

Forty subjects with GERD-compatible symptoms (pyrosis, regurgitation, dysphagia), diagnosed by clinical investigation and complementary exams, who had failed clinical treatment, were prospectively evaluated. They underwent total laparoscopic fundoplication (Nissen) between March and September 2001.

The study was approved by the local ethics and research committee of the Prontocord Hospital in Manaus, AM, Brazil, and all patients agreed to participate by signing the informed consent form.

The inclusion criteria were age between $18-70$ years and disease durationfor a minimum of six months. Patients with severe pulmonary or heart disease, coagulopathies, previous gastroesophageal surgery, esophageal aperistalsis, and morbid obesity were excluded.

Upper digestive endoscopy, contrast esophagea radiogram, esophageal manometry and prolonged esophageal $\mathrm{pH}$ monitoring, were done for preoperative evaluation of gastroesophageal reflux. The surgical indication was based on reflux symptoms and, at least, two altered complementary evaluations, regarding the following findings: hiatal hernia and/ or any level of erosive esophagitis, according to the modified Savary-Miller classification; hypotonic LES; pathological reflux and/or physiological reflux with positive symptom index.

Nissen fundoplication was done by laparoscopy in all cases. Venous and inhalation general anesthesia was used, positioning the patient in horizontal supine position and with the lower limbs slightly open, the surgeon standing between them. The abdominal cavity was accessed after $\mathrm{CO}_{2}$ pneumoperitoneum was done, inserting five portals arranged as follows: below the xiphoid appendix (5 $\mathrm{mm})$, right hypochondrium $(5 \mathrm{~mm})$, left flank $(5 \mathrm{~mm})$, left hypochondrium $(10 \mathrm{~mm})$ and supraumbilical $(10 \mathrm{~mm})$.
The diaphragmatic crura were approximated using two or three separate Ethibond 2-0 sutures, calibrated by a $36 \mathrm{~F}$ bougie. The proximal short vessels were dissected and a $360^{\circ}$ valve was constructed with the gastric fundus that circled the distal esophagus for $3 \mathrm{~cm}$, shaped by a $36 \mathrm{~F}$ Fouchet (floppy) catheter. Three or four separate Ethibond 2-0 sutures were used. All procedures, as well as pre- and postoperative evaluations were carried out by the same surgeon and team.

The surgical performance was evaluated through operative time, surgical complications and conversions rates. The efficacy of the procedure in correcting reflux was assessed at six months, on average, by clinical investigation of reflux symptoms and by the need for proton pump inhibitors (PPIs), also applying the Visick score, as follows: grade I - absence of gastrointestinal symptoms after the operation; grade II - mild symptoms, such as discomfort after meals, food intolerance, malaise, controlled with rest and dietary restriction; grade III - uncontrollable symptoms with general care, such as diarrhea, vomiting or epigastric pain, requiring medications; grade IV - symptoms equal to or worse than those prior to the operation, disease relapse or complication.

In the early postoperative period (six months), the previously mentioned complementary exams were conducted to compare with the results obtained preoperatively. There was subsequent 15-year follow-up, observing the subjects' weight progression and the possible impact of weight gain on the control of reflux symptoms. In case of morbid obesity, with or without recurrence of reflux, videolaparoscopic bariatric surgeries would be proposed and those patients excluded from the study. Late clinical evaluation of the sample, after 15 years, was carried out through clinical inquiry on the recurrence or not of reflux symptoms and the need or not of PPIs, using also the Visick score. Upper digestive endoscopy was also done to analyze the valve, alterations of the esophageal hiatus and the presence or absence of erosive esophagitis. These evaluations were stratified according to present or absent obesity. The patients were searched through telephone contact and e-mail.

\section{Statistical analysis}

The SAS (System Analysis Statistical) software was used for statistical analysis. In the quantitative data, when the hypothesis of normality was accepted, the ShapiroWilk test was used to calculate mean, standard deviation, and the Student t-test was used for paired data. When the hypothesis of normality was rejected, the median was calculated and the non-parametric Wilcoxon test applied. In the analysis of categorical variables, the chi-square test was applied or when that was not possible, the Fisher's exact test. A significance level of $5 \%$ was set for the application of statistical tests.

\section{RESULTS}

Forty individuals were preoperatively evaluated in this study, 29 of them females (72.5\%). The average preoperative GERD duration was 76 months; the average age 51 years, and the average BMI $25.68 \mathrm{~kg} / \mathrm{m}^{2}$.

Preoperative and early postoperative clinical results In the preoperative period $90 \%$ of the subjects complained of moderate pyrosis, $47.5 \%$ regurgitation and $55 \%$ dysphagia. At six months postoperatively, complaints of both pyrosis and regurgitation decreased to $2.5 \%$, and dysphagia to $7.5 \%$. Using the Visick criteria at six months, $77.5 \%$ of the subjects were classified as grade I; $15 \%$ as grade II; and $7.5 \%$ as grade III. 
Preoperative and early postoperative results of complementary exams

Endoscopy was used to evaluate hiatal hernia and esophagitis. Comparing preoperative and early postoperative data, a reduction from $97.5 \%$ to $10 \%(p<0.001)$ was found in the percentage of hernias, detecting one case of paraesophageal hernia after fundoplication. There was a reduction from $77.5 \%$ to $7.5 \%$ in esophagitis, only the cases of Barrett's esophagus remained. In postoperative follow-up esophagogram, there was a significant reduction in hiatal hernias and manometry showed an increase in the percentage of subjects with normal LES (Table 1).

TABLE 1 - Distribution according to the preoperative and early postoperative results of complementary exams

\begin{tabular}{|c|c|c|c|c|c|}
\hline \multirow{3}{*}{ Variables } & \multicolumn{4}{|c|}{ Assessment } & \multirow[b]{3}{*}{$p^{*}$} \\
\hline & \multicolumn{2}{|c|}{ Pre } & \multicolumn{2}{|c|}{ Post } & \\
\hline & $\mathrm{f}_{\mathrm{i}}$ & $\%$ & $f_{i}$ & $\%$ & \\
\hline Endoscopy- axial hiatal hernia & & & & & $<0.001$ \\
\hline Yes & 39 & 97.5 & 4 & 10.0 & \\
\hline No & 1 & 2.5 & 36 & 90.0 & \\
\hline Total & 40 & 100.0 & 40 & 100.0 & \\
\hline Esophagitis & & & & & $<0.001$ \\
\hline Yes & 30 & 75.0 & 3 & 7.5 & \\
\hline No & 10 & 25.0 & 37 & 92.5 & \\
\hline Total & 40 & 100.0 & 40 & 100.0 & \\
\hline Esophagogram- hiatal hernia & & & & & $<0.001$ \\
\hline Yes & 26 & 89.7 & 6 & 15.0 & \\
\hline No & 3 & 10.3 & 34 & 85.0 & \\
\hline Total & 29 & 100.0 & 40 & 100.0 & \\
\hline Manometry (LES tonus) & & & & & $<0.001$ \\
\hline hypotonic LES & 27 & 67.5 & 7 & 18.4 & \\
\hline normal LES & 13 & 32.5 & 31 & 81.6 & \\
\hline Total & 40 & 100.0 & 38 & 100.0 & \\
\hline
\end{tabular}

$\mathrm{f}_{\mathrm{i}}=$ absolute simple frequency; ${ }^{*} \mathrm{p}$ value in bold indicates statistical difference between proportions at $5 \%(p<0.05)$, using exact Fisher's test

There was significant $(\mathrm{p}<0.001)$ postoperative improvement in the esophageal manometry that assessed the LES tonus and its total and abdominal lengths. Significant postoperative reflux control was demonstrated in pHmetry (Table 2).

TABLE 2 - Comparison according to pre and early (six months) postoperative complementary exams

\begin{tabular}{|c|c|c|c|}
\hline Variables & \multicolumn{2}{|c|}{ Assessment } & $\mathrm{p}^{*}$ \\
\hline Manometry & Pre & Post & \\
\hline Total median LES length $(\mathrm{cm})$ & 3.6 & 4.8 & $<0.001$ \\
\hline Abdominal median LES length $(\mathrm{cm})$ & 1.2 & 3.0 & $<0.001$ \\
\hline LES median pressure $(\mathrm{mmHg})$ & 6.6 & 19.2 & $<0.001$ \\
\hline \multicolumn{4}{|l|}{ pHmetry } \\
\hline Total time $\%$ median $\mathrm{pH}<4$ & 7.5 & 0.3 & $<0.001$ \\
\hline Orthostatic \% median $\mathrm{pH}<4$ & 6.8 & 0.9 & $<0.001$ \\
\hline Supine $\%$ median $\mathrm{pH}<4$ & 6.8 & 0.4 & $<0.001$ \\
\hline
\end{tabular}

* $p$ value in bold indicates statistical difference between proportions at $5 \%(p<0.05)$, using exact Wilcoxon's test

\section{Surgical technique-related results}

Laparoscopy Nissen fundoplication was done in 40 subjects. Intraoperative and postoperative complications rates were $12.5 \%$ and $15 \%$, respectively (Table 3 ). There was one case of liver trauma from the liver retractor, causing liver bleeding and leading to conversion to laparotomy, for bleeding control. The average surgical time was $97.4 \mathrm{~min}$ and the hospital length of stay, $17.9 \mathrm{~h}$. Feeding was started on average $9 \mathrm{~h}$ after the procedure.
TABLE 3 - Frequency of trans and postoperative complications of fundoplication

\begin{tabular}{|l|c|c|}
\hline Trans operative complications & $\mathbf{n}$ & $\%$ \\
\hline Large cervical emphysema & 01 & 2.5 \\
Short vessels bleeding & 01 & 2.5 \\
Liver bleeding & 02 & 5 \\
\hline Left inferior phrenic vein injury & 01 & 2.5 \\
\hline Total & 05 & 12.5 \\
\hline Postoperative complications (within 30 days) & \multicolumn{2}{|l|}{} \\
\hline Persistent vomiting on $1^{\text {st }}$ POD & 01 & 2.5 \\
Adynamic ileus until $2^{\text {nd }}$ POD & 01 & 2.5 \\
Chest pain & 01 & 2.5 \\
Intense hiccups on $1^{\text {st }}$ POD & 01 & 2.5 \\
Paraesophageal hernia & 01 & 2.5 \\
Operative wound infection & 01 & 2.5 \\
\hline Total & 06 & 15 \\
\hline
\end{tabular}

$\mathrm{POD}=$ postoperative day

\section{Late follow-up}

After 15 years of fundoplication, clinical, endoscopic and weight aspects of 29 subjects were evaluated $(72.5 \%$ of the initial sample). It was not possible to evaluate 11 patients from the initial sample (two of them were excluded from the study after undergoing bariatric techniques, to treat obesity).

Regarding the weight change of the sample, there was a mean increase in BMI of $3.64 \mathrm{~kg} / \mathrm{m}^{2}$ in the final evaluation $(p<0.001)$, with significant development of obesity (Table 4).

Regarding the symptoms of pyrosis and regurgitation, there was a significant reduction in the late postoperative period, as compared to the preoperative (Table 4). Subjects who reported late pyrosis mentioned lower intensity and frequency, as compared to the preoperative period. There were other sporadic complaints that included dysphagia, non-cardiac chest pain, and globus.

TABLE 4 - Comparison of pre and late postoperative BMI and symptoms

\begin{tabular}{|c|c|c|c|c|c|}
\hline \multirow[t]{2}{*}{ Variables } & \multicolumn{2}{|c|}{$\begin{array}{c}\text { Preoperative } \\
\text { assessment }(n=40)\end{array}$} & \multicolumn{2}{|c|}{$\begin{array}{c}\text { 15-year follow } \\
\text { up }(n=29)\end{array}$} & \multirow[t]{2}{*}{$P$} \\
\hline & $f_{i}$ & $\%$ & $f_{i}$ & $\%$ & \\
\hline $\mathrm{BMI}\left(\mathrm{kg} / \mathrm{m}^{2}\right)$ & & & & & $<0.001^{\star}$ \\
\hline Normal weight (20-24.9) & 22 & 55.0 & 01 & 3.4 & \\
\hline Overweight (25-29.9) & 17 & 42.5 & 16 & 55.2 & \\
\hline Obesity (30-34.9) & 1 & 2.5 & 12 & 41.4 & \\
\hline Mean $\mathrm{BMI} \pm \mathrm{SD}$ & \multicolumn{2}{|c|}{$25.68 \pm 1.54$} & \multicolumn{2}{|c|}{$29.32 \pm 2.53$} & \\
\hline \multicolumn{6}{|l|}{ Symptoms } \\
\hline None & - & - & 15 & 51.7 & $<0.001^{\text {*ᄎ }}$ \\
\hline Pyrosis & 30 & 90.0 & 10 & 34.5 & $<0.001^{\text {*ᄎ }}$ \\
\hline Regurgitation & 19 & 47.5 & - & - & $<0.001^{\text {*ᄎ }}$ \\
\hline NCCP ${ }^{\star \star *}$ & 2 & 5.0 & 2 & 6.9 & $0.999 * *$ \\
\hline Dysphagia & 10 & 25.0 & 3 & 10.3 & $0.218^{\star *}$ \\
\hline Globus & 1 & 2.5 & 1 & 3.4 & $0.999^{\star \star}$ \\
\hline
\end{tabular}

$\mathrm{f}_{\mathrm{i}}=$ absolute simple frequency; $\mathrm{SD}=$ standard deviation; $\mathrm{NCCP}=$ non-cardiac chest pain; * $p$ value in bold indicates statistical difference at $5 \%(p<0.05)$, in relation to the averages, using Sudent's $t$ test, ${ }^{* \star *}=$ exact Fisher's test

Table 5 depicts the comparison between preoperative and late (15-year) endoscopic findings, demonstrating consistent persistence of surgical anatomy and effective control of erosive esophagitis.

There was one case of late esophagitis on a Barrett's patient, who persisted after fundoplication, with no histopathological dysplasia. It is important to note that two other cases of Barrett found in the preoperative period were among the subjects not evaluated at this stage. 
TABLE 5-Comparison of pre and late (15years) endoscopic findings

\begin{tabular}{|c|c|c|c|c|c|}
\hline \multirow{3}{*}{ Variables } & \multicolumn{4}{|c|}{ Assessment } & \multirow[b]{3}{*}{$p^{*}$} \\
\hline & \multicolumn{2}{|c|}{ Pre } & \multicolumn{2}{|c|}{ Late post } & \\
\hline & $f_{i}$ & $\%$ & $f_{i}$ & $\%$ & \\
\hline Esophagitis & & & & & $<0.001$ \\
\hline Yes & 30 & 75.0 & 3 & 10.3 & \\
\hline No & 10 & 25.0 & 26 & 89.7 & \\
\hline Total & 40 & 100.0 & 29 & 100.0 & \\
\hline Axial hiatal hernia & & & & & $<0.001$ \\
\hline Yes & 39 & 97.5 & 2 & 6.9 & \\
\hline No & 1 & 2.5 & 27 & 93.1 & \\
\hline Total & 40 & 100.0 & 29 & 100.0 & \\
\hline
\end{tabular}

$\mathrm{f}=$ absolute simple frequency; ${ }^{*} \mathrm{p}$ value in bold indicates statistical difference between proportions at $5 \%(p<0.05)$, using exact Fisher's test

Table 6 depicts the late comparative assessment between the patients who developed obesity and those who did not, considering clinical and endoscopic findings, the level of satisfaction with the surgical results according to the Visick scale, as well as the need to use PPIs. On such assessments no statistical difference was found between the two groups.

TABLE6-Comparison of clinical and endoscopic variables regarding late (15 years) postoperative weight

\begin{tabular}{|c|c|c|c|c|c|c|}
\hline \multirow{3}{*}{ Variables } & \multicolumn{4}{|c|}{ Obesity } & \multirow{3}{*}{ Total } & \multirow{3}{*}{$p^{*}$} \\
\hline & \multicolumn{2}{|c|}{ Yes $(n=12)$} & \multicolumn{2}{|c|}{ No $(n=17)$} & & \\
\hline & fi & $\%$ & fi & $\%$ & & \\
\hline Esophagitis & & & & & & 0.998 \\
\hline Yes & 1 & 8.3 & 2 & 11.8 & 3 & \\
\hline No & 11 & 91.7 & 15 & 88.2 & 26 & \\
\hline Hiatal hernia & & & & & & 0.999 \\
\hline No & 11 & 91.7 & 16 & 94.1 & 27 & \\
\hline Yes & 1 & 8.3 & 1 & 5.9 & 2 & \\
\hline Use of PPls & & & & & & 0.999 \\
\hline Yes & 6 & 50.0 & 8 & 47.1 & 14 & \\
\hline No & 6 & 50.0 & 9 & 52.9 & 15 & \\
\hline Visick classification & & & & & & 0.919 \\
\hline 1 & 6 & 50.0 & 9 & 52.9 & 15 & \\
\hline$\|$ & 5 & 41.7 & 6 & 35.3 & 11 & \\
\hline III & 1 & 8.3 & 2 & 11.8 & 3 & \\
\hline Symptoms & & & & & & 0.999 \\
\hline None & 6 & 50,0 & 9 & 52,9 & 15 & \\
\hline Pyrosis & 5 & 41,7 & 5 & 29,5 & 10 & \\
\hline NCCP & 1 & 8,3 & 1 & 5,9 & 2 & \\
\hline Dysphagia & 1 & 8,3 & 2 & 11,8 & 3 & \\
\hline Globus & 1 & 8,3 & - & - & 1 & \\
\hline
\end{tabular}

$\mathrm{f}_{\mathrm{i}}=$ absolute simple frequency; ${ }^{*}=$ exact Fisher's test, $\mathrm{NCCP}=$ non-cardiac chest pain

\section{DISCUSSION}

GERD is usually approached through clinical treatment, intending to control reflux symptoms and heal esophagitis. Surgical treatment, on the other hand, has the additional objectives of restoring the anatomy and function of the gastroesophageal transition ${ }^{21}$.

However, some uncertainties remain regarding the surgical procedure in respect to the durability of its results and to its side effects ${ }^{28}$. There are, therefore, still controversies regarding the indication of fundoplication for the treatment of GERD. ${ }^{28,30}$ According to Holscher et al. ${ }^{12}$ surgical intervention would take place when adequate clinical control of reflux was not obtained, a parameter used in the current study, consonant to other authors ${ }^{1,6}$.

The introduction of the minimally invasive method for correction of gastroesophageal reflux has optimized its surgical indication ${ }^{8,21}$. Intraoperative complication rates range from $2-13 \%$ and conversion rates from $1-10 \% 5$. The complication rates of this study are consistent with the literature, with zero mortality.

There is controversy as to the type of valve to be used for the correction of reflux, and they may totally or partially encircle the gastroesophageal transition ${ }^{4,18,31,32}$. In a systematic review Ramos et al. ${ }^{25}$ concluded that partial fundoplication has fewer obstructive side effects as compared to total. In contrast, supporters of the total fundoplication (Nissen) state that this type of valve is more effective in containing reflux $x^{5,21}$. In the current study, only total fundoplication was used.

Ciovica et al. ${ }^{7}$ evaluated 550 patients who underwent laparoscopic fundoplication with a one-year postoperative follow-up. They found improvement in GERD symptoms and quality of life, only $3.2 \%$ of cases requiring antiacids. Moore et al. ${ }^{18}$ demonstrated that surgical treatment of GERD has good reflux control, with improvement of symptoms in $85-93 \%$ of cases, favorably impacting quality of life. In the current sample, in early postoperative evaluation there was significant improvement in complaints of pyrosis and regurgitation using the Visick's criteria ${ }^{5,27,32}$ to grade improvement in reflux symptoms.

In the early postoperative period of this study there was significant reduction in hiatal hernias and remission of esophagitis; however, consonant to the literature ${ }^{17,33}$, the cases of Barrett's esophagus persisted and do not seem to regress after surgery, deserving systematic follow-up.

Short-term postoperative $\mathrm{pHmetry} \mathrm{indicated} \mathrm{physiological}$ reflux in all cases, demonstrating effective reflux control, corroborating some authors ${ }^{11,16}$. At esophageal manometry, significant LES restoration was noted regarding its length and pressure, indicating the importance of the operation in restoring the functionality of the gastroesophageal transition 28 .

The esophagogram was conducted in all cases in the early postoperative period in order to evaluate the anatomy of the gastroesophageal transitional region and to verify the position and extension of the valve. Paraesophageal hiatal hernia was detected in one case. Awad et al. ${ }^{2}$ reinforce the importance of barium esophagogram in the diagnosis and routine postoperative follow-up of these hernias.

Some authors document the relief of typical symptoms (pyrosis and regurgitation) at prolonged follow-up after surgical correction of GERD ${ }^{11}$ and demonstrate the superiority of the operation over clinical treatment ${ }^{7}$. Specheler et al 28 stated, however, that in the long term the operation is not so effective in containing reflux, and a substantial number of patients will need antiacids. According to Lundell et $a l^{16}$. this condition may indicate increased esophageal sensitivity to reflux without necessarily being pathological, which can be assessed by pHmetry. In the current sample, it was noted later that $62.5 \%$ of symptomatic subjects had no endoscopic evidence of reflux, which could reflect increased esophageal sensitivity. This cannot be confirmed, however, given that pHmetry was not employed at this stage of the evaluation, which is a limitation of this study.

In the last decades weight gain has been a worldwide trend ${ }^{23}$, a fact also seen in subjects submitted to fundoplication ${ }^{14}$. Some authors reported that weight gain is a predictive factor of recurrence of reflux symptoms after fundoplication, either due to increased intra-abdominal pressure, valve migration or rupture ${ }^{1,14,22}$, what is not corroborated by other authors ${ }^{10}$ or by this sample. In this study, after subjects stratification according to present or absent development of late obesity, there was no significant correlation between weight gain and relapse of reflux symptomatology or anatomical alteration of fundoplication after clinical and endoscopic evaluation. The use of PPIs was on demand, equal in the obese and non-obese, in a restricted portion of the sample, consonant with some studies ${ }^{7,11}$, and dissonant from others ${ }^{6}$. The use 
of the Visick criteria ${ }^{27}$ in the late phase of this evaluation, demonstrated that good results were sustained, even in subjects who developed obesity.

The weight gain that follows the antireflux operation is usually late, and the average time for the development of obesity is six years, with possible indication of bariatric surgery ${ }^{14}$, consistent with the findings of this study. Conversion to bariatric technique may be indicated by reflux recurrence, obesity, or both ${ }^{15,22}$, and should be carried out by an experienced surgical team. ${ }^{29}$. In this series, $41.4 \%$ of the subjects who were followed long term, developed grade I obesity $(p<0.0001)$.

The small sample size of this series, as well as the absence of a control group, represents limitations of this study, precluding conclusive inferences regarding results, and other studies are recommended to confirm or not these findings.

\section{CONCLUSION}

Laparoscopic fundoplication proved to be a safe procedure, resulting in long lasting efficient control of gastroesophageal reflux. Weight gain in late follow-up did not hinder reflux symptoms control or the anatomic preservation of the valve.

\section{REFERENCES}

1. Andolfi C, Vigneswaran Y, Kavitt Rt, Herbella Fa, Patti Mg. Laparoscopic Antireflux Surgery: Importance Of Patient's Selection And Preoperative Workup. Journal Of Laparoendoscopic \& Advanced Surgical Techniques Part A. 2017;27(2):101-5.

2. Awad Zt, Magee Dj, Wanis N, Firozvi A. Type Iv Hiatal Hernia Post Laparoscopic Nissen Fundoplication: Report Of A Case. Surgery Today. 2001;31(2):156-8.

3. Braghetto,IAndCsendes,A.FailureAfterFundoplication:Re-Fundoplication? Is There A Room For Gastrectomy? In Which Clinical Scenaries?. Abcd, Arq. Bras. Cir. Dig., 2019, Vol.32, No.2. Issn 0102-6720

4. Broeders Ja, Bredenoord Aj, Hazebroek Ej, Broeders la, Gooszen Hg, Smout Aj. Effects Of Anti-Reflux Surgery On Weakly Acidic Reflux And Belching. Gut. 2011;60(4):435-41.

5. CadiereGb, Houben Jj, BruynsJ,HimpensJ,PanzerJm, GelinM.Laparoscopic Nissen Fundoplication: Technique And Preliminary Results.the British Journal Of Surgery. 1994;81(3):400-3.

6. Campos Gm, Peters Jh, Demeester Tr, Oberg S, Crookes Pf, Tan S, Et Al. Multivariate Analysis Of Factors Predicting Outcome After Laparoscopic NissenFundoplication.Journal OfGastrointestinal Surgery:Official Journal Of The Society For Surgery Of The Alimentary Tract. 1999;3(3):292-300

7. Ciovica R, Riedl O, Neumayer C, Lechner W, Schwab Gp, Gadenstatter M. The Use Of Medication After Laparoscopic Antireflux Surgery. Surgical Endoscopy. 2009;23(9):1938-46.

8. DallemagneB, WeertsJm, Jehaes C,MarkiewiczS, Lombard R. Laparoscopic Nissen Fundoplication: Preliminary Report. Surgical Laparoscopy \& Endoscopy. 1991;1(3):138-43.

9. Devault Kr, Castell Do. Guidelines For The Diagnosis And Treatment Of Gastroesophageal RefluxDisease.PracticeParameters CommitteeOfThe American College Of Gastroenterology. Archives Of Internal Medicine. 1995; 155(20):2165-73.

10. Fraser J, Watson Di, O'boyle Cj, Jamieson Gg. Obesity And Its Effect On Outcome Of Laparoscopic Nissen Fundoplication. Diseases Of The Esophagus : Official Journal Of The International Society For Diseases Of The Esophagus / Isde. 2001;14(1):50-3.

11. Gee Dw, Andreoli Mt, Rattner Dw. Measuring The Effectiveness Of Laparoscopic Antireflux Surgery: Long-Term Results. Archives OfSurgery (Chicago, III : 1960). 2008;143(5):482-7.

12. HolscherAh, BollschweilerE, GutschowC. [GerdAndComplications:When IsSurgery Necessary?].ZeitschriftFurGastroenterologie.2007;45(11):1150-5.

13. Johansson J, Johnsson F, Joelsson B, Floren Ch, Walther B. Outcome 5 Years After 360 Degree Fundoplication For Gastro-Oesophageal Reflux Disease. The British Journal Of Surgery. 1993;80(1):46-9.
14. Kellogg Ta, Andrade R, Maddaus $M$, Slusarek B, Buchwald H, lkramuddin $\mathrm{S}$. Anatomic Findings And Outcomes After Antireflux Procedures In Morbidly Obese Patients Undergoing Laparoscopic Conversion To RouxEn-Y Gastric Bypass. Surgery For Obesity And Related Diseases: Official Journal Of The American Society For Bariatric Surgery. 2007;3(1):52-7; Discussion 8-9.

15. Khan A, Kim A, Sanossian C, Francois F. Impact Of Obesity Treatment On Gastroesophageal Reflux Disease. World Journal Of Gastroenterology. 2016;22(4):1627-38.

16. Lundell L, Miettinen P, Myrvold He, Hatlebakk Jg, Wallin L, Engstrom C, Et Al. Comparison Of Outcomes Twelve Years After Antireflux Surgery Or Omeprazole Maintenance Therapy For Reflux Esophagitis. Clinical GastroenterologyAnd Hepatology:TheOfficial Clinical Practice JournalOf TheAmerican Gastroenterological Association.2009;7(12):1292-8; Quiz60.

17. Marano S, Mattacchione S, Luongo B, Paltrinieri G, Mingarelli V, Tosato F. Barrett's Esophagus After Laparoscopic Nissen-Rossetti Fundoplication: Functional Evaluation. Minerva Chirurgica. 2011;66(6):517-25.

18. Moore M, Afaneh C, Benhuri D, Antonacci C, Abelson J, Zarnegar R. Gastroesophageal RefluxDisease:AReviewOfSurgical Decision Making World Journal Of Gastrointestinal Surgery. 2016;8(1):77-83.

19. Moraes-Filho Jp, Chinzon D, Eisig Jn, Hashimoto Cl, Zaterka S. Prevalence Of Heartburn And Gastroesophageal Reflux Disease In The Urban Brazilian Population. Arquivos De Gastroenterologia. 2005;42(2):122-7.

20. Nonino, Cb Et Al. Is There Any Change In Phenotypic Characteristics Comparing 5 To 10 Years Of Follow-Up In Obese Patients Undergoing Roux-En-Y Gastric Bypass?. Abcd, Arq. Bras. Cir. Dig., 2019, Vol.32, No.3. Issn 0102-6720

21. Patti Mg, Robinson T, Galvani C, Gorodner Mv, Fisichella Pm, Way Lw. Total Fundoplication Is Superior To Partial Fundoplication Even When Esophageal Peristalsis Is Weak.journal Of The American College Of Surgeons. 2004;198(6):863-9; Discussion 9-70.

22. PerezAr, MoncureAc, RattnerDw.ObesityAdverselyAffects TheOutcome Of Antireflux Operations. Surgical Endoscopy. 2001;15(9):986-9.

23. PrenticeAm. TheEmerging Epidemic OfObesity InDeveloping Countries. international Journal Of Epidemiology. 2006;35(1):93-9.

24. Raftopoulos I, Awais O, Courcoulas Ap, Luketich Jd. Laparoscopic Gastric Bypass After Antireflux Surgery For The Treatment Of Gastroesophageal Reflux In Morbidly Obese Patients: Initial Experience.obesity Surgery. 2004;14(10):1373-80.

25. Ramos Rf, Lustosa Sa, Almeida Ca, Silva Cp, Matos D. Surgical Treatment Of Gastroesophageal Reflux Disease: Total Or Partial Fundoplication? Systematic Review And Meta-Analysis.arquivos De Gastroenterologia. 2011:48(4):252-60.

26. Resa Jj, Solano J, Fatas Ja, Blas JI, Monzon A, Garcia A, Et Al. Laparoscopic Biliopancreatic DiversionWithDistal Gastric Preservation:TechniqueAnd Three-Year Followup.journal Of Laparoendoscopic \&Advanced Surgical Techniques Part A. 2004;14(3):131-4.

27. Rijnhart-De Jong Hg, Draaisma Wa, Smout Aj, Broeders la, Gooszen Hg. The Visick Score: A Good Measure For The Overall Effect Of Antireflux Surgery? Scandinavian Journal Of Gastroenterology. 2008;43(7):787-93.

28. Spechler Sj, Lee E, Ahnen D, Goyal Rk, Hirano I, Ramirez F, Et Al. LongTerm OutcomeOfMedical And Surgical Therapies ForGastroesophageal Reflux Disease: Follow-Up Of A Randomized Controlled Trial. Jama. 2001;285(18):2331-8.

29. Stefanidis D, Hope Ww, Kohn Gp, Reardon Pr, Richardson Ws, Fanelli Rd. Guidelines For Surgical Treatment Of Gastroesophageal Reflux Disease. Surgical Endoscopy. 2010:24(11):2647-69.

30. Vakil N, VanZantenSV, Kahrilas P, Dent J, Jones R. The Montreal Definition And Classification Of Gastroesophageal Reflux Disease: A Global, Evidence-Based Consensus Paper]. Zeitschrift Fur Gastroenterologie. 2007:45(11):1125-40.

31. Walker Sj, Holt S, Sanderson Cj, Stoddard Cj. Comparison Of Nissen Total And Lind Partial Transabdominal Fundoplication In The Treatment Of Gastro-OesophagealReflux.theBritishJournalOfSurgery. 1992;79(5):410-4.

32. Watson A, Spychal Rt, Brown Mg, Peck N, Callander N. Laparoscopic 'Physiological' AntirefluxProcedure: Preliminary Results OfAProspective Symptomatic And Objective Study.the British Journal Of Surgery. 1995;82(5):651-6.

33. Zaninotto G, Portale G, Costantini M, Fiamingo P, Rampado S, Guirroli E, Et Al. Objective Follow-Up After Laparoscopic Repair Of Large Type lii Hiatal Hernia. Assessment Of Safety And Durability.world Journal Of Surgery. 2007;31(11):2177-83.

34. Zilberstein, B, Santo, M A And Carvalho, M H. Critical Analysis Of Surgical Treatment Techniques OfMorbid Obesity. Abcd, Arq. Bras. Cir. Dig., 2019, Vol.32, No.3. Issn 0102-6720 